\title{
Towards medium-resolution brightness temperature retrieval from active and passive microwave
}

\author{
X. Wu ${ }^{\text {a }}$, J. P. Walker ${ }^{\text {a }}$, C. Rüdiger ${ }^{\text {a }}$, R. Panciera ${ }^{\text {b }}$, A. Monerris ${ }^{\text {a }}$, N. N. Das ${ }^{\text {c }}$ \\ ${ }^{a}$ Department of Civil Engineering, Monash University, Clayton, VIC 3800, Australia \\ ${ }^{b}$ Cooperative Research Centre for Spatial Information, Melbourne, VIC 3053, Australia \\ ${ }^{c}$ Jet Propulsion Laboratory, California Institute of Technology, Pasadena, CA 91109 USA \\ Email: xiaoling.wu@monash.edu
}

\begin{abstract}
Given the importance of soil moisture for hydrological applications, including weather and flood forecasting, the Soil Moisture and Ocean Salinity (SMOS) mission was launched by the European Space Agency in 2009. This first-ever dedicated global soil moisture mapping mission has a target accuracy of $0.04 \mathrm{v} / \mathrm{v}$. The passive microwave remote sensing approach has been adopted for this mission due to its high sensitivity to near-surface soil moisture, applicability to all weather conditions, direct correlation with the soil dielectric constant, and reduced effects by vegetation and roughness. However, passive microwave (radiometer) observations suffer from being relatively low spatial resolution, on the order of $40 \mathrm{~km}$. It is proposed that this scale issue may be overcome by using active microwave (radar) observations, and this is the approach being taken by NASA's Soil Moisture Active Passive (SMAP) mission, with a scheduled launch in late 2014. The rationale behind SMAP is that the synergy between active and passive observations can be used in a downscaling approach to overcome the individual limitations of each observation type, and ultimately provide a soil moisture data set at intermediate resolution $(\sim 10 \mathrm{~km})$. The objective of this study is to test an existing downscaling approach, which has thus far received very limited testing, using airborne and satellite data, thus analyzing its viability for application.
\end{abstract}

The downscaling approach tested in this paper is based on an observed near-linear relationship between active and passive observations, and theoretically proven to be an effective method. The rationale is to downscale low resolution $(40 \mathrm{~km})$ brightness temperature $(\mathrm{Tb})$ to an intermediate resolution using high resolution $(1 \mathrm{~km})$ radar backscatter $(\sigma)$, with soil moisture retrieval subsequently applied to the downscaled brightness temperature data. There are three components to this study: i) preliminary estimation of a slope parameter $\mathrm{B}_{\mathrm{C}}$ from a regression analysis of time-series $\mathrm{Tb}$ and $\sigma$ data at $40 \mathrm{~km}$ resolution; ii) merging coarse resolution $\mathrm{Tb}$ and high resolution $\sigma$ using a linear function with the slope $\mathrm{B}_{\mathrm{C}}$; and iii) validate the downscaled $\mathrm{Tb}$ with airborne data. In this application, data from the C-band Advanced Synthetic Aperture Radar (ASAR) with approximately $1 \mathrm{~km}$ resolution are used to downscale L-band SMOS Tb data at the $40^{\circ}$ incidence angle. The downscaled results are then evaluated using airborne Tb collected at $1 \mathrm{~km}$ resolution within the framework of the Soil Moisture Active Passive Experiments (SMAPEx) project over a $40 \mathrm{~km} \times 40 \mathrm{~km}$ area in south-eastern Australia.

Results show that the Root-Mean-Square Error (RMSE) in Tb at $1 \mathrm{~km}$ resolution downscaled using SMOS and ASAR is $11.7 \mathrm{~K}$ at h-polarization and $10.3 \mathrm{~K}$ at v-polarization, respectively. When downscaled to $10 \mathrm{~km}$ resolution, the RMSE is reduced to $7.8 \mathrm{~K}$ and $6.9 \mathrm{~K}$, respectively, showing an improvement in the RMSE of $\sim 4 \mathrm{~K}$. However, both results have errors larger than desired. This is mainly due to the ASAR_GM mode only being available in hh-polarization, while it has been shown that the best results from applying this downscaling algorithm can be expected from radar observations at vv-polarization. Some other reasons for such a result when using ASAR data may include: i) it is C-band that is more affected by vegetation, ii) the instrument is relatively noisy in Global Mode, iii) the incidence angle of the normalized backscatter is $30^{\circ}$ rather than $40^{\circ}$. In addition, the SMOS data are relatively noisy $(6 \mathrm{~K}-7 \mathrm{~K})$ compared to that expected from SMAP $(1.3 \mathrm{~K})$, and there is an offset in the overpass time of ASAR and SMOS of approximately 6 hrs. However, applying this downscaling algorithm similar to that being developed for SMAP shows little potential for the downscaling of SMOS with ASAR_GM data, unless the parameter $\mathrm{B}_{\mathrm{C}}$, which was considered to be constant within the entire SMAPEx domain, can be derived at sub SMOS pixel scale.

Keywords: Downscaling, Brightness temperature, Radar backscatter, PLMR, ASAR, SMOS 


\section{INTRODUCTION}

Soil moisture is of great importance to global water cycle monitoring and prediction, especially in agriculture, hydrology and meteorology (Wagner et al. 2003). With the development of remote sensing technology (Schmugge et al. 2002), soil moisture mapping is becoming much easier and more accurate over large areas when compared with traditional monitoring by in situ networks of stations. Consequently, methods are being developed to make use of this emerging soil moisture information to constrain numerical model prediction of soil moisture (Shi et al. 2009), and hence improve the forecasting of weather and floods, leading to significant national benefit.

Over the past decade, passive microwave remote sensing has become generally accepted as the most accurate approach for soil moisture mapping, due to its stronger and more direct connection between the observed brightness temperature $(\mathrm{Tb})$ and the surface soil moisture $(\sim 5 \mathrm{~cm})$, than with active microwave sensing (radar backscatter) or thermal data (Kerr 2007). The best results were found at low frequency $(\sim 1.4 \mathrm{GHz})$ due to the reduced effects by the atmosphere, surface roughness and vegetation attenuation, and the increased observation depth. Consequently, the Soil Moisture and Ocean Salinity (SMOS) mission (Kerr et al. 2010) was launched by the European Space Agency in 2009, as the first satellite dedicated to soil moisture measurement using L-band. Despite the high sensitivity of this passive microwave radiometer approach to near-surface soil moisture monitoring, it suffers from its relatively low spatial resolution, which is on the order of $40 \mathrm{~km}$. Since active microwave observations (despite being less sensitive to changes in soil moisture due to the confounding effects of vegetation and surface roughness) have a much higher spatial resolution, NASA is developing the Soil Moisture Active Passive (SMAP) mission (Entekhabi et al. 2010) scheduled to be launched in Nov 2014. The rationale behind SMAP is that the synergy between active and passive observations can be used in a downscaling approach to overcome the individual limitations of each observation, ultimately providing a soil moisture data set at resolutions deemed suitable for hydrometeorological applications $(\sim 10 \mathrm{~km})$.

One of the proposed downscaling method to be applied in the SMAP mission is based on the assumed nearlinear relationship between radar backscatter $(\sigma)$ and radiometer brightness temperature $(\mathrm{Tb})$, and has been proven as an effective method using the airborne Passive and Active L-band System (PALS) instrument dataset collected during the Soil Moisture Experiments, 2002 (SMEX'02; Das et al. 2011). Other methods, such as the Bayesian merging algorithm (Zhan et al. 2006) and the optical downscaling method (Merlin et al. 2008) have also shown great potential in downscaling. While the Bayesian merging method is yet to be demonstrated with real data, the optical approach can only be applied under non-cloudy conditions and requires land surface models with a wide range of ancillary data. Consequently, the objective of this paper is to evaluate the effectiveness of the linear brightness temperature downscaling method with radar backscatter, using L-band operational radiometer (SMOS) and C-band radar (ASAR) data.

\section{DATA}

The Soil Moisture Active Passive Experiments (SMAPEx; Monerris et al. 2011) field site and data sets have been chosen for testing the downscaling performance. The SMAPEx study site $\left(-34.67^{\circ} \mathrm{N},-35.01^{\circ} \mathrm{N}\right.$, $145.97^{\circ} \mathrm{E}, 146.36^{\circ} \mathrm{E}$ ) in Figure 1 aims to simulate data from the SMAP mission, including a SMOS/SMAP sized radiometer footprint (approximately $40 \mathrm{~km} \times 40 \mathrm{~km}$ ) over landscape typical of south-eastern Australia. The SMAPEx data were collected using a new airborne remote sensing capability which allows undertaking high resolution active and passive microwave remote sensing at Lband similar to those expected from SMAP. The facility includes the Polarimetric L-band Multibeam Radiometer (PLMR) and the Polarimetric L-band Imaging Scatterometer (PLIS) which, when used together on the same aircraft, allow the simulation of SMAP data. SMAPEx comprises a total of three campaigns undertaken over a one year timeframe (winter, summer, and crop growing season). The data of PLMR used in this study are collected in the first

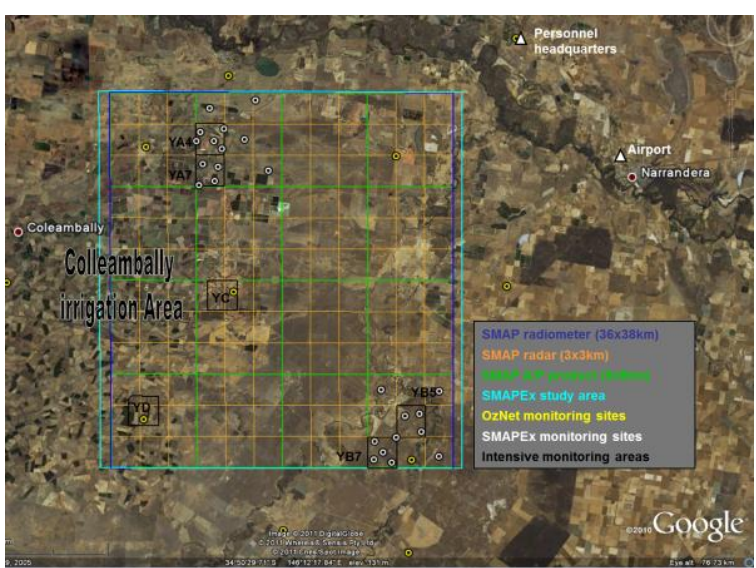

Figure 1. SMAPEx study area, south-eastern Australia: approximately $40 \mathrm{~km} \times 40 \mathrm{~km}$ in size. 
The reprocessed L-band Level 1C brightness temperature product of SMOS has an average resolution of 40 $\mathrm{km}$ on a resampled $15 \mathrm{~km}$ grid, while the C-band backscatter dataset from ASAR is available at $1 \mathrm{~km}$ resolution. The ASAR data are often available for the same day as SMOS overpasses, and are therefore used as input data for executing the downscaling procedure tested here. Subsequently, the airborne PLMR data from the SMAPEx field campaign are used as the reference Tb data at high $(1 \mathrm{~km})$ spatial resolution, having an accuracy estimated to be better than $1 \mathrm{~K}$ at h-polarization and $2.5 \mathrm{~K}$ at v-polarization (Panciera 2009). The PLMR data are therefore used to evaluate the downscaled $\mathrm{Tb}$ and hence the effectiveness of the downscaling algorithm when using ASAR data together with data from SMOS at $40^{\circ}$ incidence angle, thus testing the viability of this downscaling method in future applications, both in the context of downscaling SMOS and in preparation for SMAP.

As the radar and radiometer sensors are onboard different satellites, coincident overpasses of the SMAPEx study area for each satellite were first identified. For the purpose of establishing a linear regression between $\mathrm{Tb}$ and backscatter, all available data were searched for coincident SMOS and ASAR overpasses having full coverage over the SMAPEx study area (regardless of the presence of coincident PLMR validation data). However, for the sake of validating the downscaled $\mathrm{Tb}$, only SMOS/ASAR overpasses coincident with PLMR flights could be used.

Concurrent dates for the two satellites are listed in Table 1 . The $6^{\text {th }}$ July and $10^{\text {th }}$ July are therefore the only dates that could be used to validate the viability of the downscaling algorithm. Any potential limitation due to the available dates will be discussed later. The standard deviation of SMOS observations with their center point falling within the $40 \mathrm{~km}$ SMAPEx area at $40^{\circ}$ incidence angle ranged from 1.1 to $6.9 \mathrm{~K}$ depending on the date and polarization, while the standard deviation of aggregated ASAR data coincident with the SMOS pixels ranged from 0.07 to $0.27 \mathrm{~dB}$. The mean and standard deviation for SMOS and ASAR data are shown in Figure 2.

Since the values of PLMR are influenced by physical temperature and incidence angle variations across the flight, the PLMR data have been normalized to a $40^{\circ}$ incidence angle and temperature corrected to the effective temperature of 20:30pm (in UTC; average overpass time of SMOS) following the methodology of Jackson (2001). Moreover, there is a warm bias in SMOS as compared to PLMR data averaged over the same footprint, being approximately $11.5 \mathrm{~K}$ at h-pol and $8.5 \mathrm{~K}$ at v-pol when assessed over the Murrumbidgee catchment (Rüdiger et al. 2011). Consequently, SMOS data were de-biased with respect to PLMR data for the purpose of crossvalidating the downscaled $\mathrm{Tb}$, and hence the debiased SMOS data are used in this study for downscaling.

\section{METHODOLOGY}

The downscaling method used in this paper is based on a linear relationship between active and passive observations at the same scale (Das et al. 2011), with a rationale of merging high-accuracy but coarseresolution passive microwave observations of $\mathrm{Tb}$ with low accuracy but fine resolution active microwave observations of $\sigma$, to ultimately obtain

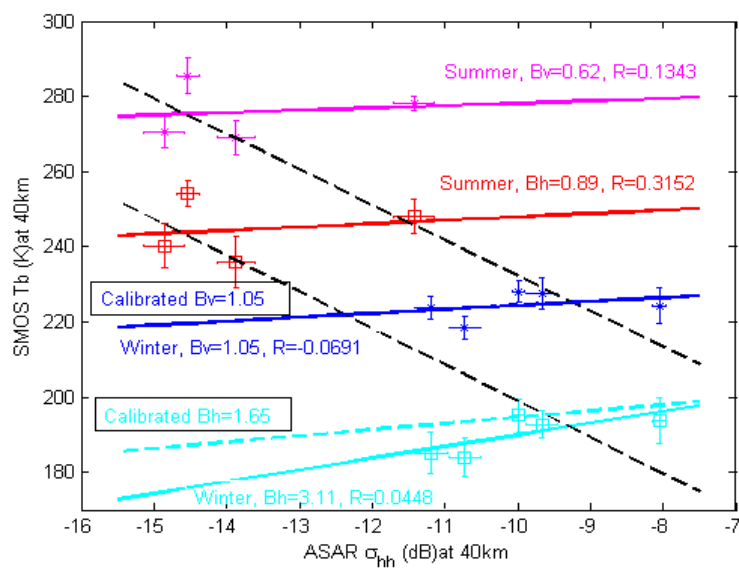

Figure 2. Scatter plot between ASAR $\sigma_{\text {hh }}$ and SMOS $\mathrm{Tb}_{\mathrm{h}} / \mathrm{Tb}_{\mathrm{v}}$ in SMAPEx area in winter and in summer: four solid colored lines are the fits in each season at each pol; two dashed black lines are fits across a year at each pol; two dashed colored lines are calibrated fits in winter. the downscaled $\mathrm{Tb}$ both at h-pol and v-pol at a medium resolution. In the following the naming convention of ' $\mathrm{C}$ ' (coarse), 'F' (fine), and 'M' (medium) is used for the SMOS L1C_Tb (40 km), ASAR backscatter $\sigma$ (1 $\mathrm{km}$ ), and downscaled Tb grid scales (1 to $10 \mathrm{~km})$, respectively. Implementation of this method first requires a linear regression of the available data to derive the coefficients of the relationship

$$
\mathrm{Tb}_{\mathrm{p}, \mathrm{C}}=\mathrm{A}_{\mathrm{C}}+\mathrm{B}_{\mathrm{C}} \times \sigma_{\mathrm{pp}, \mathrm{C}}
$$


where $\mathrm{p}$ indicates the polarization of $\mathrm{Tb}$, including $\mathrm{h}$ - and $\mathrm{v}$-pol; $\mathrm{pp}$ means co-polarization of radar observations $\sigma$, including hh or vv-pol. Correlations between 4 different combinations of $\mathrm{Tb}_{\mathrm{p}}$ and $\sigma_{\mathrm{pp}}$ have been analyzed (Das et al. 2011). From that study $\sigma_{\mathrm{vv}}$ is expected to correlate best with $\mathrm{Tb}$ at both $\mathrm{h}$ and v-pol than $\sigma_{\mathrm{hh}}$. However, ASAR backscatter is only available at hh-pol and is thus used to downscale SMOS data in this paper. In addition, the study of Das et al. (2011) showed that Tb at v-pol rather than at h-pol is expected to have a higher degree of correlation with $\sigma_{\mathrm{hh}}$. The influence of this polarization limitation from ASAR will be illustrated in the results. The value for $\sigma_{\mathrm{pp}, \mathrm{C}}$ is obtained by aggregating $1 \mathrm{~km}$ resolution ASAR within the coarse footprint $\mathrm{C}$ (in $\mathrm{dB}$ ), with $\mathrm{Tb}_{\mathrm{p}, \mathrm{C}}$ directly from the SMOS L1C product (in $\mathrm{K}$ ). At a given scale, parameters $A_{C}$ and $B_{C}$, which in reality depend on vegetation cover and type as well as surface roughness, are assumed time-invariant and homogenous over the entire SMAPEx area in this paper. Therefore, those two parameters at scale C can be estimated by using SMOS L1C_Tb and ASAR $\sigma_{\text {hh }}$ data time-series.

In order to downscale to scale $\mathrm{F},(1)$ can be written as

$$
\mathrm{Tb}_{\mathrm{p}, \mathrm{F}}=\mathrm{A}_{\mathrm{F}}+\mathrm{B}_{\mathrm{F}} \times \sigma_{\mathrm{pp}, \mathrm{F}},
$$

where $\mathrm{Tb}_{\mathrm{p}, \mathrm{F}}$ is the brightness temperature value at a spatial scale of $\mathrm{F}$ for a particular pixel within $\mathrm{C}$, and $\sigma_{\mathrm{pp}, \mathrm{F}}$ is the corresponding backscatter value from the ASAR. While the default implementation of this algorithm assumes that $\mathrm{A}$ and $\mathrm{B}$ are homogeneous within $\mathrm{C}$, in reality it is likely that they vary spatially as a result of different vegetation types and land management practices among others. In this case $A_{F}$ and $B_{F}$ have the same values as $A_{C}$ and $B_{C}$. By averaging both sides of (2), one obtains

$$
<\mathrm{Tb}_{\mathrm{p}, \mathrm{F}}>=<\mathrm{A}_{\mathrm{F}}>+<\mathrm{B}_{\mathrm{F}}>\times<\sigma_{\mathrm{pp}, \mathrm{F}}>,
$$

Here $<>$ is used to indicate averaging across $\mathrm{C}$, which yields $\left\langle\mathrm{Tb}_{\mathrm{p}, \mathrm{F}}\right\rangle=\mathrm{Tb}, \mathrm{c}$, as each smaller pixel within $\mathrm{C}$ shares the same value of SMOS Tb at that scale. Subtracting (3) from (2), and considering A and B are homogeneous and therefore equal at each scale, the downscaled $\mathrm{Tb}$ at scale $\mathrm{F}$ can be obtained as

$$
\mathrm{Tb}_{\mathrm{p}, \mathrm{F}}=\mathrm{Tb}_{\mathrm{p}, \mathrm{C}}+\mathrm{B}_{\mathrm{C}} \times\left(\sigma_{\mathrm{pp}, \mathrm{F}}-\sigma_{\mathrm{pp}, \mathrm{C}}\right) \text {, }
$$

Using (4) the downscaled $\mathrm{Tb}$ is obtained for each pixel in the SMAPEx area at $1 \mathrm{~km}, 4 \mathrm{~km}$ and $10 \mathrm{~km}$ resolution, by averaging the ASAR data at $1 \mathrm{~km}$ resolution. Clearly, the downscaled $\mathrm{Tb}$ at fine resolution is heavily dependent on the quality of the SMOS Tb, the relative backscatter difference within the coarse grid, and the relationship with $\mathrm{Tb}$ as represented by the regression slope that are added to the background value.

The downscaled results at different resolutions are evaluated by comparing them with PLMR Tb data at 1 $\mathrm{km}, 4 \mathrm{~km}$, and $10 \mathrm{~km}$ resolution, respectively, in order to assess the merit of this downscaling method in preparation for SMAP and its potential application to SMOS and ASAR. However, it should be noted that this downscaling algorithm differs from that being developed for SMAP due to limitations in the ASAR data. Specifically, it does not make use of cross-polarized backscatter data that has been shown to account for land management variability (Das et al. 2011).

\section{RESULTS}

Given the hypothesis of a time-invariant and homogeneous $B_{C}$ across the SMAPEx area, the time series of SMOS Tb and ASAR $\sigma$ were used to estimate $\mathrm{B}_{\mathrm{C}}$, using 4 days from summer, together with 12 days from winter (see Table 1). The parameter $\mathrm{B}_{\mathrm{C}}$ (with the unit of $\mathrm{K} / \mathrm{dB}$ ) was determined to be -9.68 at h-pol and -9.43 at v-pol (dashed lines in Figure 2) and subsequently applied to the proposed downscaling algorithm for the SMOS and ASAR data on $6^{\text {th }}$ and $10^{\text {th }}$ July. When comparing with PLMR Tb, the RMSE of downscaled Tb at $1 \mathrm{~km}$ resolution is $22.1 \mathrm{~K}$ at h-pol, and $19.7 \mathrm{~K}$ at v-pol on $6^{\text {th }} \mathrm{July}$. Subsequently, $\mathrm{B}_{\mathrm{C}}$ was estimated separately for each season, thus reducing the time invariance assumption to a few weeks. In austral summer, a 4-day time series of SMOS and ASAR data $\left(29^{\text {th }}\right.$ Jan., $11^{\text {th }}$ Feb., $14^{\text {th }}$ Feb., $17^{\text {th }}$ Feb. $)$ has been utilized to perform a linear regression, while in winter a 5-day time series (in July) has been used. In this case, $\mathrm{B}_{\mathrm{C}}$ is 3.11 at h-pol and 1.05 at v-pol in winter, and 0.89 at h-pol and 0.62 at v-pol in summer, being significantly different from the previous estimates of $\mathrm{B}_{\mathrm{C}}$ when using data in summer and winter together, see Figure 2. Accordingly, applying $\mathrm{B}_{\mathrm{C}}$ obtained from the time series in winter to perform downscaling on days $6^{\text {th }}$ and $10^{\text {th }}$ July, resulted in a RMSE of $12.8 \mathrm{~K}$ at h-pol and $10.5 \mathrm{~K}$ at v-pol on $6^{\text {th }}$ July, being an improvement of $\sim 10 \mathrm{~K}$ over the previous result.

These results suggest that $\mathrm{B}_{\mathrm{C}}$ is time-variant with considerable difference according to season, and significant impact on the resultant retrieval of downscaled $\mathrm{Tb}$. Further analysis of $\mathrm{B}_{\mathrm{C}}$ is of great importance to control the accuracy of downscaled $\mathrm{Tb}$. The variation of $\mathrm{B}_{\mathrm{C}}$ in a smaller area than SMAPEx was therefore analysed. This was achieved by dividing the SMAPEx area into sixteen $10 \mathrm{~km} \times 10 \mathrm{~km}$ areas and retrieving $\mathrm{B}_{\mathrm{C}}$ from time-series SMOS $(10 \mathrm{~km})$ and ASAR $(10 \mathrm{~km})$ data over each area. According to the results in Figure 3, the 
ID of each pixel is labelled starting from the top left corner, and moving sequentially across the study area (Figure 1) from west to east, followed by north to south. The value of $\mathrm{B}_{\mathrm{C}}$ clearly varies across study site, mainly because the left part of SMAPEx is dominated by cropping area, while the right part is mostly grazing (less irrigation), suggesting that the hypothesis of a constant $\mathrm{B}_{\mathrm{C}}$ (dashed lines in Figure 3) over the radiometer pixel may result in poor estimates of downscaled Tb. A summary of the RMSE of downscaled $\mathrm{Tb}$ derived from de-biased SMOS and ASAR data is shown in Table 2, together with the comparison between de-biased SMOS Tb data and aggregated PLMR data (at $40 \mathrm{~km}$ resolution).

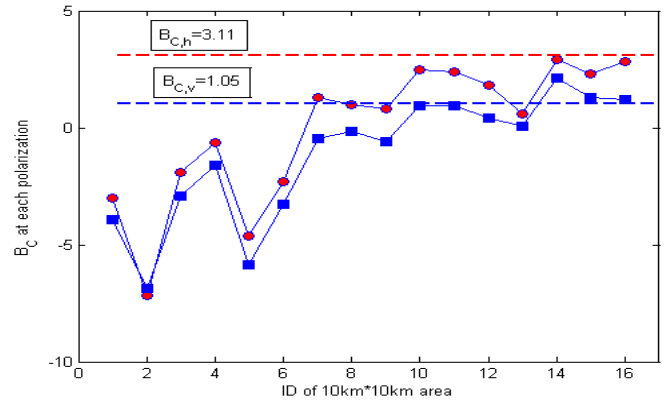

Figure 3. Variation of $B_{C}$ in 16 smaller areas with a $10 \mathrm{~km} \times 10 \mathrm{~km}$ size within the SMAPEx

In order to eliminate any residual bias or "noise/error" in the SMOS data as compared to PLMR over SMAPEx on the specific downscaling date, estimates of SMOS observations were then obtained from aggregating the $1 \mathrm{~km}$ PLMR data directly.

Table 2. Difference between de-biased SMOS and aggregated PLMR data, and RMSE of downscaled Tb

\begin{tabular}{|c|c|c|c|c|c|}
\hline Date & Polarization & PLMR Tb (K) & De-biased SMOS Tb (K) & Difference (K) & RMSE of Downscaled Tb (K) \\
\hline \multirow{2}{*}{$6^{\text {th }}$ July } & h-pol & 196.5 & 202.0 & -5.5 & 12.8 \\
\cline { 2 - 6 } & v-pol & 230.8 & 233.3 & -2.5 & 10.5 \\
\hline \multirow{2}{*}{$10^{\text {th }}$ July } & h-pol & 212.7 & 208.1 & 4.6 & 11.2 \\
\cline { 2 - 6 } & v-pol & 242.5 & 240.7 & 1.8 & 8.8 \\
\hline
\end{tabular}

However, because only 2 days of coincident PLMR and ASAR data are available, the $\mathrm{B}_{\mathrm{C}}$ parameter estimated previously using time-series de-biased SMOS Tb and ASAR $\sigma_{\mathrm{hh}}$ data were used in the analysis that follows. Consequently, the aggregated PLMR Tb at $40 \mathrm{~km}$ were only used as the value of $T b_{\mathrm{p}, \mathrm{C}}$ in equation (4), meaning that the PLMR Tb at $1 \mathrm{~km}$ resolution collected from $6^{\text {th }}$ and $10^{\text {th }}$ July are first aggregated to $40 \mathrm{~km}$, and then downscaled by $1 \mathrm{~km}$ ASAR backscatter $\sigma_{\mathrm{hh}}$ to $1 \mathrm{~km}, 4 \mathrm{~km}$ and $10 \mathrm{~km}$ respectively, using the SMOS derived estimates of $\mathrm{B}_{\mathrm{C}}$ (3.11 at h-pol and 1.05 at v-pol).

As mentioned before, PLMR and ASAR have different characteristics in frequency band, polarization and incidence angle, and their mappings over SMAPEx area on $6^{\text {th }}$ July are shown in Figure 4. It can be found that in the up-right quarter of each figure, PLMR and ASAR show similar pattern, while in the remaining area those two patterns turn out to be approximately flipped, indicating the downscaled $\mathrm{Tb}$ will be poor due to those inconsistent patterns no matter what estimates of $\mathrm{B}_{\mathrm{C}}$ are. Accordingly, detailed downscaled $\mathrm{Tb}$ and evaluation of the feasibility of the downscaling algorithm are as follows:
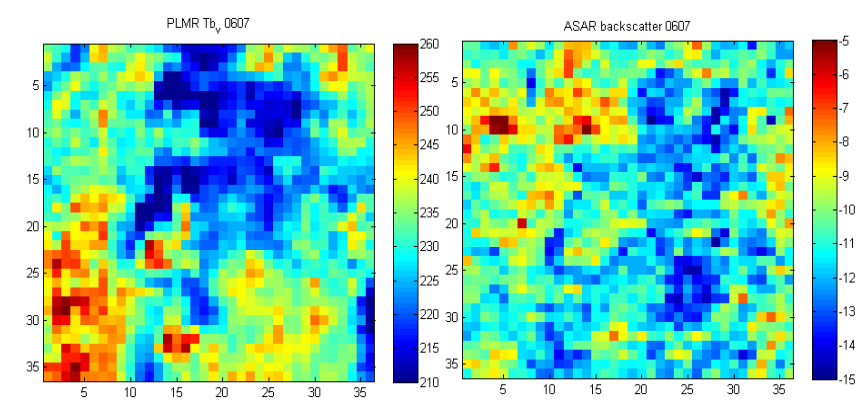

Figure 4. PLMR Tb at v-pol and ASAR data on $6^{\text {th }}$ July in the SMAPEx study area

Downscaled $T b_{y}$ on 0607

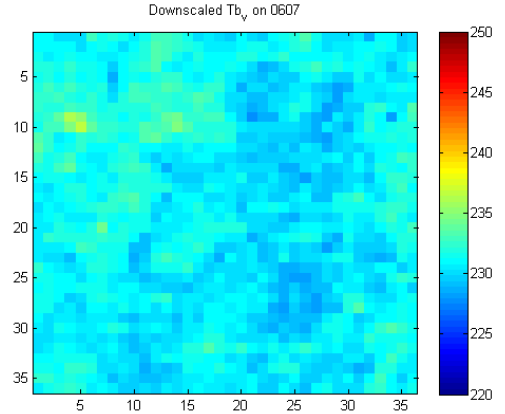

Downscaled $\mathrm{Tb}_{\mathrm{y}}$ on 0607

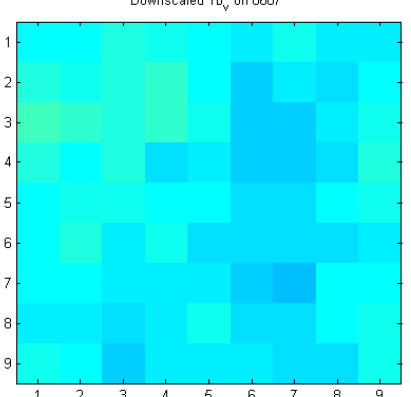

Downscaled $T b_{y}$ on 0607

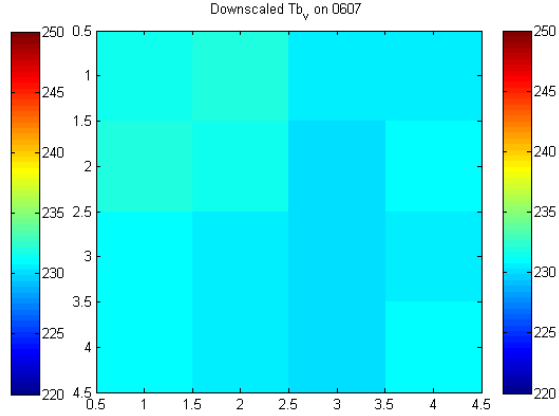

Figure 5. Downscaled Tb at v-pol on $6^{\text {th }}$ July in SMAPEx domain: at $1 \mathrm{~km}, 4 \mathrm{~km}$ and $10 \mathrm{~km}$ resolution. 
Comparing values of PLMR $\mathrm{Tb}$ at each polarization between the two days shows a clear increase in brightness temperature on $10^{\text {th }}$ July (illustrated in Table 3), which implies a drying of the soil and/or increase in soil temperature. Meanwhile, ASAR data show a decrease in average backscatter on $10^{\text {th }}$ July. With respect to the downscaled $\mathrm{Tb}$, a similar drying tendency as PLMR Tb turns out from $6^{\text {th }}$ to $10^{\text {th }} \mathrm{July}$.

Table 3. RMSE of downscaled Tb obtained by merging PLMR and ASAR data on $6^{\text {th }}$ and $10^{\text {th }}$ July

\begin{tabular}{|c|c|c|c|c|c|c|c|}
\hline Date & Pol. & $\begin{array}{c}\text { Aggregated } \\
\text { PLMR }(\mathrm{K}) \text { at } 40 \\
\mathrm{~km} \text { resolution }\end{array}$ & $\begin{array}{c}\text { Aggregated } \\
\text { ASAR }(\mathrm{dB}) \text { at } \\
40 \mathrm{~km} \text { resolution }\end{array}$ & $\begin{array}{c}\text { Aggregated } \\
\text { Downscaled } \mathrm{Tb}(\mathrm{K}) \\
\text { at } 40 \mathrm{~km} \text { resolution }\end{array}$ & $\begin{array}{l}\text { RMSE }(\mathrm{K}) \\
\text { at } 1 \mathrm{~km} \\
\text { resolution }\end{array}$ & $\begin{array}{l}\text { RMSE }(\mathrm{K}) \\
\text { at } 4 \mathrm{~km} \\
\text { resolution }\end{array}$ & $\begin{array}{l}\text { RMSE }(\mathrm{K}) \\
\text { at } 10 \mathrm{~km} \\
\text { resolution }\end{array}$ \\
\hline \multirow[t]{2}{*}{$6^{\text {th }}$ July } & h-pol & 196.5 & \multirow[t]{2}{*}{-10.7} & 196.4 & 11.7 & 9.6 & 7.8 \\
\hline & v-pol & 230.8 & & 230.8 & 10.3 & 8.5 & 6.9 \\
\hline \multirow[t]{2}{*}{$10^{\text {th }}$ July } & h-pol & 212.7 & \multirow[t]{2}{*}{-11.2} & 212.4 & 10.0 & 7.6 & 6.1 \\
\hline & V-pol & 242.5 & & 242.4 & 8.6 & 6.7 & 5.2 \\
\hline
\end{tabular}

Values of RMSE given in Table 3 show an improvement from 1-km to 10-km resolution for both days. Downscaled $\mathrm{Tb}$ data at $1-\mathrm{km}$ resolution are the results from implementation of this downscaling method, while downscaled $\mathrm{Tb}$ data at $4 \mathrm{~km}$ and $10 \mathrm{~km}$ resolution have used ASAR data averaged to $4 \mathrm{~km}$ or $10 \mathrm{~km}$ resolution, respectively.

In comparison with the de-biased SMOS results (Table 2), the aggregated PLMR data used here have a better performance. For example, comparison of the results for $6^{\text {th }}$ July shows an RMSE improvement of approximately $2 \mathrm{~K}$. Moreover, the downscaled results at v-pol are better than h-pol. Compared with the correlation of $\mathrm{Tb}_{\mathrm{h}}$ and $\sigma_{\mathrm{hh}}, \mathrm{Tb}_{\mathrm{v}}$ and $\sigma_{\mathrm{hh}}$ have a better linear relationship, thus indicating it is more suitable for application in this downscaling algorithm. However, the accuracy of downscaled results still suffer from a single polarization of ASAR data, and results are expected to improve for application with vv-pol and crosspol backscatter.

All of the results above have been based on a $B_{C}$ value derived from de-biased SMOS and ASAR data, which is 3.11 at $\mathrm{h}$-pol and 1.05 at $\mathrm{v}$-pol, respectively. In order to test the sensitivity to this parameter, the downscaling method is repeated with a "calibrated" $\mathrm{B}_{\mathrm{C}}$, obtained by minimising the RMSE between downscaled and observed $\mathrm{Tb}$ at $1 \mathrm{~km}$ resolution. The calibrated value of $\mathrm{B}_{\mathrm{C}}$, expected to obtain an optimal downscaled $\mathrm{Tb}$, is estimated as 1.65 at h-pol and 1.05 at v-pol (dashed coloured lines in Figure 2). While the value at h-pol is obviously different to that determined earlier in Figure 2, the resultant RMSE is not considerably better: at $1 \mathrm{~km}$ the RMSE is $11.4 \mathrm{~K}$ at h-pol and $10.2 \mathrm{~K}$ at $\mathrm{V}$-pol on $6^{\text {th }} \mathrm{July}$, and $9.9 \mathrm{~K}$ at h-pol and $8.6 \mathrm{~K}$ at v-pol on $10^{\text {th }}$ July.

\section{DISCUSSION AND CONCLUSION}

The objective of this study was to test the feasibility of an existing downscaling approach, using operational SMOS and ASAR datasets. It is shown that the accuracy of the downscaling approach is primarily determined by the pattern agreement of the radar and radiometer observations, as imposed by the $B_{C}$ parameter. In addition, the downscaled $\mathrm{Tb}$ accuracy relies to a large extent on the accuracy of the radiometerbased coarse resolution $(40 \mathrm{~km}) \mathrm{Tb}$ inputs, as demonstrated by comparing inputs from SMOS and aggregated PLMR. Moreover the C-band ASAR $\sigma_{\mathrm{hh}}$ data used in this study indicates little potential for downscaling, confirming earlier results that backscatter at hh-pol has poor correlation with $\mathrm{Tb}$ (vv-pol is expected to yield better results), greatly limiting the effectiveness of this downscaling algorithm.

In this paper the value of $\mathrm{B}_{\mathrm{C}}$ is estimated using regression on pairs of $\mathrm{Tb}$ and $\sigma$ data at the same resolutions collected within the SMAPEx area. The robustness of $B_{C}$ is subjected to the number of available $\mathrm{Tb}$ and $\sigma$ data pairs. Future studies will aim at improved parameterization of $\mathrm{B}_{\mathrm{C}}$ using more pairs of radar and radiometer data for linear regression, which is expected to perform better for downscaling. The variation of $\mathrm{B}_{\mathrm{C}}$ with seasons is illustrated, and therefore $\mathrm{B}_{\mathrm{C}}$ must be applied based on the specific land surface conditions, in order to ensure the accuracy of downscaled results. Another issue pertaining to $B_{C}$ is the size of study area. Since $B_{C}$ is related to vegetation type, surface roughness, land management and other factors, the robustness of its value is affected by the heterogeneity of the study area. At the beginning of this study, $\mathrm{B}_{\mathrm{C}}$ was assumed to be time-invariant and homogenous in the entire area, which increased the errors obtained with the downscaling algorithm. It is envisioned that a significant improvement could derive from adjusting the $B_{C}$ parameter using high-resolution ancillary data on vegetation in future studies, which might improve the results of the downscaling to some degree. 
The error of the downscaled $\mathrm{Tb}$ can be reduced by averaging to a larger scale, e.g. 4-km and 10-km, mainly because the speckle noise from ASAR is decreased during averaging, as well as the patchiness in vegetation. In conclusion, results from this study indicate that SMOS Tb and ASAR $\sigma_{\text {hh }}$ data generally do not meet the accuracy requirement for this downscaling algorithm, resulting in a downscaled RMSE of not better than $5 \mathrm{~K}$ at $10 \mathrm{~km}$ reslution. Future studies will focus on evaluating the viability of this proposed downscaling algorithm, by applying more accurate radar and radiometer data in specific month/season with similar frequencies, polarizations and incidence angle to SMAP. To achieve better downscaled results, studies will also be carried out on parameterization of $\mathrm{B}_{\mathrm{C}}$ using auxillary vegetation characteristics.

\section{ACKNOWLEDGEMENTS}

The SMAPEx field campaigns and related research development have been funded by Australian Research Council (DP0984586). The authors acknowledge the collaboration of a large number of scientists from throughout Australia and around the world, and in particular of key personnel from the SMAP team which provided significant contribution to the campaign's design and execution.

\section{REFERENCES}

Das, N. N., D. Entekhabi, E. G. Njoku. (2011). An algorithm for merging SMAP radiometer and radar data for high-resolution soil moisture retrieval. IEEE Transactions on Geoscience and Remote Sensing, 49(5), 1504-1512.

Entekhabi, D., E. G. Njoku, et al. (2010). The Soil Moisture Active Passive (SMAP) Mission. Proceedings of the IEEE, 98(5), 704-716.

Jackson, T. (2001). Multiple resolution analysis of L-Band brightness temperature for soil moisture. IEEE Transactions on Geoscience and Remote Sensing, 39(1), 151-164.

Jackson, T. J., A. Y. Hsu, P. E. O'Neill. (2002). Surface soil moisture retrieval and mapping using highfrequency microwave satellite observations in the Southern Great Plains. Journal of Hydrometeorology, 3(6), 688-699.

Kerr, Y. (2007). Soil moisture from space: Where are we? Hydrogeology Journal, 15(1), 117-120.

Kerr, Y., P. Waldteufel, et al. (2010). The SMOS Mission: New tool for monitoring key elements of the global water cycle. Proceedings of the IEEE, 98(5), 666-687.

Merlin, O., J. P. Walker, A. Chehbouni, Y. Kerr. (2008). Towards deterministic downscaling of SMOS soil moisture using MODIS derived soil evaporative efficiency. Remote Sensing of Environment, 112(10), 3935-3946.

Monerris, A., J. P. Walker, et al. (2011). The soil moisture active passive experiments. International Conference on Modeling and Simulation (MODSIM), Perth, WA, Australia, 12-16 December 2011, Conference Proc.

Panciera, R. (2009). Effect of land surface heterogeneity on satellite near-surface soil moisture observations. Ph.D. thesis, The University of Melbourne.

Rüdiger, C., J. P. Walker, et al. (2011). Validation of the level 1c and level 2 SMOS products with airborne and ground-based observations. International Conference on Modeling and Simulation (MODSIM), Perth, WA, Australia, 12-16 December 2011, Conference Proc.

Schmugge, T. J., W. P. Kustas, J. C. Ritchie, T. J. Jackson, A. Rango. (2002). Remote sensing in hydrology. Advances in Waster Resources 25, 1367-1385.

Shi, X. K., J. Wen, et al. (2009). Application of satellite microwave remote sensed brightness temperature in the regional soil moisture simulation. Hydrol. Earth Syst. Sci.Discuss, 6(1), 1233-1260.

Wagner, W., K. Scipal, et al. (2003). Evaluation of the agreement between the first global remotely sensed soil moisture data with model and precipitation data. J. Geophys. Res, 108(D19), 4611.

Zhan, X., P. R. Houser, J. P. Walker, W. T. Crow. (2006). A method for retrieving high-resolution surface soil moisture from hydros L-band radiometer and radar observation. IEEE Transactions on Geoscience and Remote Sensing, 44(6), 1534-1544. 